Original Research Paper

\title{
Evaluation of the Cytisus Triflorus (Lam.) Polyphenols Cicatrizing Activity on Experimental Thermal Burns in New Zealand Rabbits
}

\author{
${ }^{1}$ Sihem Khadri, ${ }^{1}$ Nafissa Boutefnouchet, ${ }^{2}$ Youcef Hadef and ${ }^{3,4}$ Zouhir Djerrou \\ ${ }^{1}$ Laboratory of Applied Microbiology and Biochemistry, \\ Department of Biochemistry, Faculty of Sciences, Badji Mokhtar University, Annaba, Algeria \\ ${ }^{2}$ Chemistry Analytical Laboratory, Department of Pharmacy, Faculty of Medicine, \\ Badji Mokhtar University, Annaba, Algeria \\ ${ }^{3}$ Pharmacotoxicology Laboratory, Institute of Veterinary Sciences, Mentouri Constantine University, Algeria \\ ${ }^{4}$ Department of Nature and Life Sciences, Faculty of Sciences, University of August $20^{\text {th }}, 1955$ Skikda, Algeria
}

Article history

Received: 25-01-2018

Revised: 01-04-2018

Accepted: 11-05-2018

Corresponding Author:

Zouhir Djerrou

Department of Nature and Life

Sciences, Faculty of Sciences,

University of August 20th,

1955 Skikda, Algeria

Email: zouhir21265@yahoo.fr

\begin{abstract}
The present study aimed to evaluate the healing properties of the medicinal plant Cytisus triflorus widely used in the traditional treatment of wound healing. The principle of study is the application of the polyphenol extract of this plant prepared with vaseline in the form of a dermal ointment on thermal burns of second deep degree (circular of $379.94 \mathrm{~mm}^{2}$ in diameter) previously caused experimentally by a hot cylindrical metal on the backs of new Zealand rabbits. Each rabbit receives four burns two dorsal and two lumbar which were treated immediately after burning with a quantity of $0.5 \mathrm{~g}$ of vaseline (positive control), $0.5 \mathrm{~g}$ of commercial ointment skin MEBO (reference), $0.5 \mathrm{~g}$ of poly phenolic extract and untreated burn served as a negative control. The treatments were done daily until the complete epithelialization of the wound. The evaluation of the healing process was based on the healing time and the burn contraction percentage calculated every two days. According to the obtained results, the vaseline shows a better percentage of burn contraction during the inflammatory phase $\left(2^{\text {nd }}-6^{\text {th }}\right.$ day) with a significant effect $(p<0.05)$ as compared to the reference drug MEBO and the Polyphenol extract that stimulated burn contraction from the $8^{\text {th }}$ day (end of the inflammatory phase) significantly compared with vaseline and untreated burns. However, poly phenolic extract significantly appears to be more effective than the reference drug by shortening the epithelialization period (19 days) as compared to other products; MEBO drug (20 days), pure vaseline (24 days) and untreated burns (25 days). The study concludes that Cytisus triflorus polyphenols promote burn wound healing in rabbit's model.
\end{abstract}

Keywords: Cytisus triflorus, Skin Burns, Polyphenols, New Zealand Rabbits

\section{Introduction}

The empirical use of medicinal plants in the treatment of wounds and burns is well recognized in most countries. These plants constitute an immense reservoir of new potential medicinal compounds with a great diversity of chemical structure and biological activities (Guilbaud et al., 1993). Indeed, polyphenols are natural compounds widely used in the plant kingdom; they represent one of the groups of secondary metabolites which have an increasing importance thanks to their beneficial effects on health (Koechlin-Ramonatxo, 2006). In recent years these compounds have aroused great interest because of their composition of flavonoids which are compounds with strong antioxidant properties (Rice-Evans et al., 1995) and phenolic acids which have interesting biological properties: anti-inflammatory, antibacterial, antiseptic, antiradical, immunostimulant (Bruneton, 1993).

Cytisus triflorus (Lam) plant, locally known as "Ilougui" belongs to the Fabaceae family; it is the most widespread species among the 8 species growing naturally throughout the north of Algeria (Ait-KaciAourahoun et al., 2015). Preliminary phytochemical screening of the plant shows the presence of a wide variety of chemical structures 
including terpenes, tannins, flavonoids, phenolic acids, alkaloids and coumarins (Ait-KaciAourahoun et al., 2015). However, it constitutes an immense reservoir of biological activities of which it traditionally represents a remedy of several affections. It is used to treat abdominal pain, wound healing, antifungal, hypotensive and antidiabetic (Sundararajan et al., 2014; Ait-kaciAourahoun et al., 2015).

The main aim of study is to provide a scientific justification of the traditional use of C. triflorus in the healing of burns; we have tested the healing activity of polyphenols extracted from this plant on thermal burns experimentally induced on the skin of New Zealand rabbit's model.

\section{Materials and Methods}

\section{Products}

Total polyphenols extracted from dry leaves of the medicinal plant Cytisus triflorus Lam., harvested from Collo region of Skikda province, by maceration in an $80 \%$ hydro-methanolic solution in three successive days with renewal of solvent every $24 \mathrm{~h}$. The solvent/plant material ratio was (10/1: $\mathrm{mL} / \mathrm{g})$ (Marston and Hotsmann, 2006).

Pure Vaseline (100\%) and MEBO commercial ointments were purchased from a private pharmacy. Vaseline was used as an excipient in the preparation of a dermal ointment based on our polyphenolic extract. MEBO (lot: 020101, expiration date: 15 Feb. 2020) was served as a reference drug. Each $100 \mathrm{~g}$ of MEBO contains: $0.25 \mathrm{~g}$ of B-sitosterol (active substance), sesame oil and beeswax (excipients).

\section{Laboratory Animals}

The study was conducted on eight New Zealand healthy males rabbits, weighing $1.62 \mathrm{Kg} \pm 0.21$ at the start of the experiment, purchased from a private farm located in El Harrouch, Skikda. The animals were kept in individual cages and acclimatized for three weeks before the test; they were kept under normal conditions of humidity, temperature and lighting with free access to water and food (ad libitum).

\section{Experimental Protocol}

Our work was carried out according to the technique described by Hamdi-Pacha et al. (2002).

\section{Application of Burns}

Rabbits were tagged in the head in order to identify them. The back of each rabbit was shaved with a depilatory cream five days before the application of burns. Each rabbit received on its back four circular burns (Fig. 1 and 2) distributed on both sides of the thoracolumbar spine, 2 dorsal (left and right) and 2 lumbar (left and right). The application of thermal burns of $22 \mathrm{~mm}$ diameter was made after local anesthesia of areas to be burned with UNICAINE at $2 \%$.

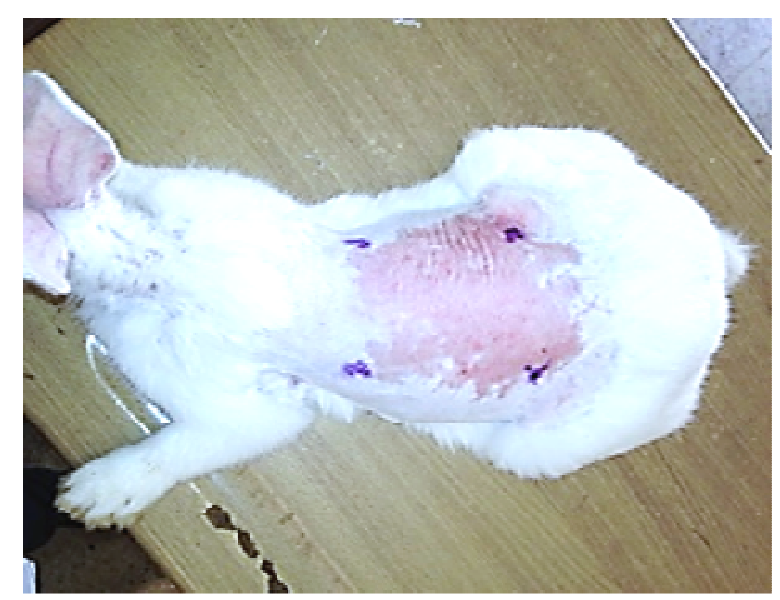

Fig. 1: Location of burns on the back of each rabbit

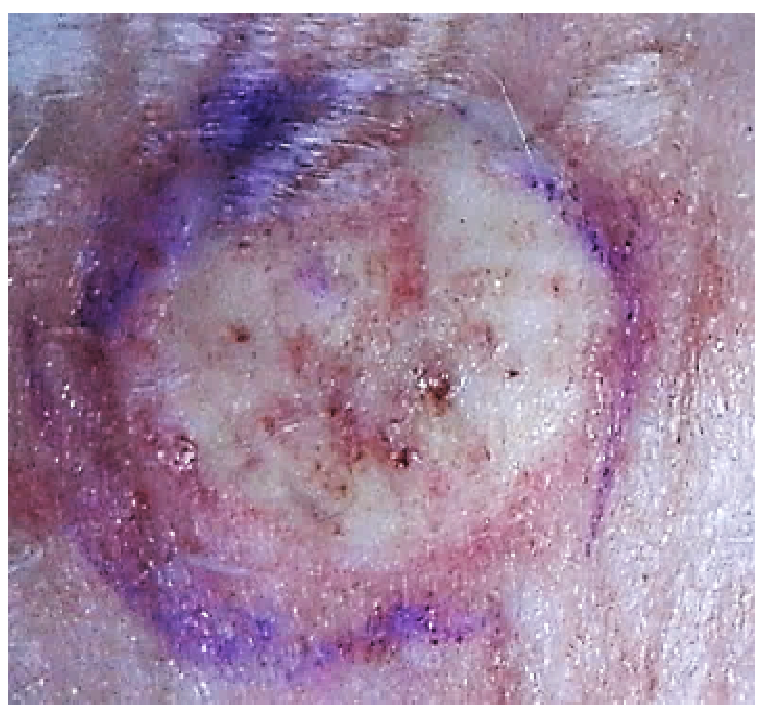

Fig. 2: Circular burn on the back of a rabbit

\section{Burn's Treatment}

The tested products were applied immediately after performing burns topically at a dose of $0.5 \mathrm{~g} / 379.94 \mathrm{~mm}^{2}$. The treatments were repeated once daily until complete epithelialization takes place:

Wound 1: Received polyphenolic extract mixed with vaseline

Wound 2: Treated with MEBO ointment and served as a reference wound

Wound 3: Treated with vaseline gel and served as a positive control

Wound 4: Received no treatment and served as a negative control

\section{Evaluation of the Healing Process}

Our study was based on two evaluation criteria: healing time and evolution of the wound surface. We proceeded to 
measure the percentage of the contraction of the wounds every 2 days according to the following equation:

Percentage of burn contraction $=($ initial area of burn - area of burn of day $n) \times 100 /$ initial area of burn (Srivastava and Durgaprasad, 2008)

\section{Statistical Analysis}

The results obtained are analyzed statistically using the Minitab program16, the data were expressed as mean \pm standard deviation. The student's test is used to compare the effectiveness of our tested products whose significance threshold was set at $\mathrm{p}<0.05$.

\section{Results}

The rabbits survived throughout the experimental period. All animals were in good health, no mortality or clinical signs are noted. The different products tested did not significantly modify the body evolution of the rabbits.

On day zero, all burns had the same diameter and the same signs of inflammation. The observation of the evolution of the burns treated with the different products has shown a decrease of their surfaces over time, this reduction is in variable chronology according to each type of treatment. The results obtained are shown in Table 1 and Fig. 3-5 as a percentage of wound contraction calculated every 2 days.

During the inflammatory phase from day 2 to day 6 (Fig. 1 and Table 1), the percentage of contraction in wounds treated with vaseline is better (with a significant effect) than those recorded during treatment with the polyphenol extract and the commercial drug $\mathrm{MEBO}$, the lowest rate of contraction is noted in untreated wounds.

From the $12^{\text {th }}$ day to the $18^{\text {th }}$ day, the result shows that both MEBO product and the polyphenolic extract stimulate the contraction of the wound significantly $(\mathrm{p}<0.05)$ as compared with Vaseline and untreated wounds. However, polyphenolic extract seems to be more efficient than MEBO. The epithelialization period (Fig. 4) was significantly shorter in burns treated with polyphenol extract compared to vaseline and untreated wounds. Finally, the longest healing time was obtained in untreated burns.

Table 1: Percentages of wound contraction at different intervals in burns treated and untreated burns

\begin{tabular}{|c|c|c|c|c|c|c|c|c|c|}
\hline \multirow[b]{2}{*}{$(\mathrm{n}=8)$} & \multicolumn{9}{|c|}{ Wound contraction (\%) Mean \pm SD } \\
\hline & $2^{\text {nd }}$ day & $4^{\text {th }}$ day & $6^{\text {th }}$ day & $8^{\text {th }}$ day & $10^{\text {th }}$ day & $12^{\text {th }}$ day & $14^{\text {th }}$ day & $16^{\text {th }}$ day & $18^{\text {th }}$ day \\
\hline VAS & $22,488 \pm 13,699$ & $30,384 \pm 10,847$ & $33,345 \pm 15,735$ & $40,385 \pm 8,963$ & $45,32 \pm 9,394$ & $51,571 \pm 10,985$ & $55,19 \pm 13,961$ & $61,573 \pm 17,720$ & $83,331 \pm 10,408$ \\
\hline CRL & $3,866 \pm 5,377$ & $5,972 \pm 8,180$ & $8,67 \pm 12,193$ & $16,632 \pm 14,773$ & $22,093 \pm 5,598$ & $50,519 \pm 4,397$ & $54,401 \pm 8,057$ & $59,994 \pm 13,736$ & $70,522 \pm 16,093$ \\
\hline MEB & $11,631 \pm 7,5$ & $16,368 \pm 5,5$ & $18,606 \pm 11,295$ & $24,922 \pm 12,580$ & $34,398 \pm 11,676$ & $57,296 \pm 9,323$ & $68,942 \pm 5,715$ & $80,063 \pm 13,647$ & $86,84 \pm 15,620$ \\
\hline POLY & $12,289 \pm 12,764$ & $21,567 \pm 8,042$ & $23,87 \pm 12,038$ & $44,465 \pm 8,485$ & $55,519 \pm 11,776$ & $64,994 \pm 11,165$ & $81,576 \pm 5,099$ & $90,985 \pm 16,213$ & $93,771 \pm 9,866$ \\
\hline
\end{tabular}

POLY: Burns treated with polyphenols, VAS: Burns treated with pure vaseline, MEB: Burns treated with MEBO ointment and CRL: Untreated burns (control)

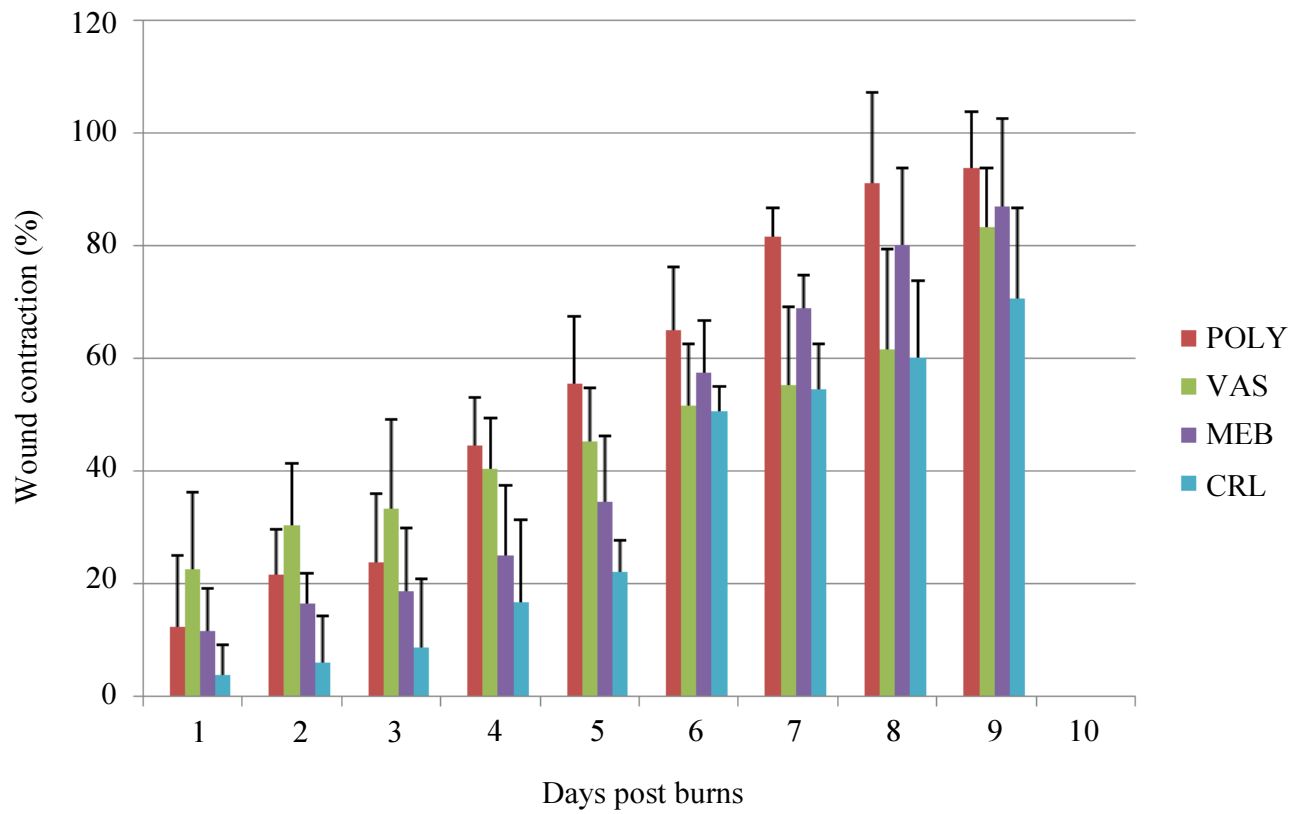

Fig. 3: Contraction percentages of wounds in treated burns and untreated burns; POLY: Burns treated with polyphenols, VAS: Burns treated with pure vaseline, MEB: Burns treated with MEBO ointment and CRL: Untreated burns (control) 


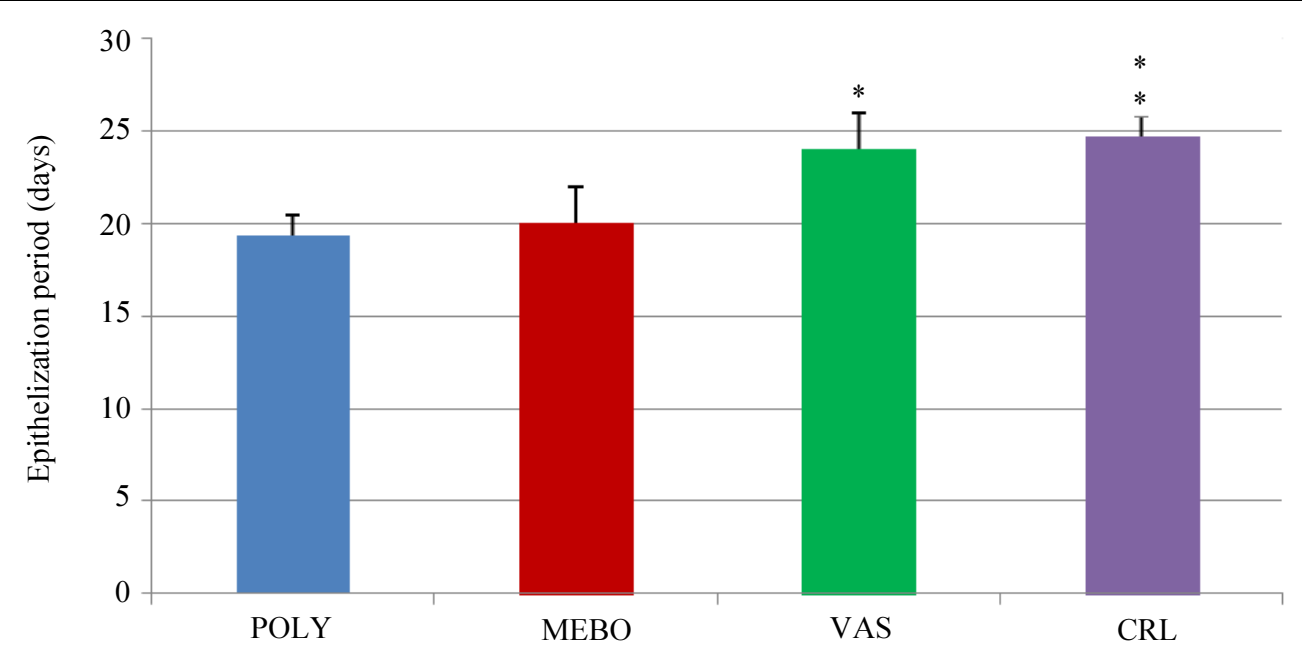

Fig. 4: Duration of wound healing (days); POLY: Burns treated with polyphenols, VAS: Burns treated with pure vaseline, MEB: Burns treated with MEBO ointment and CRL: Untreated burns (control)
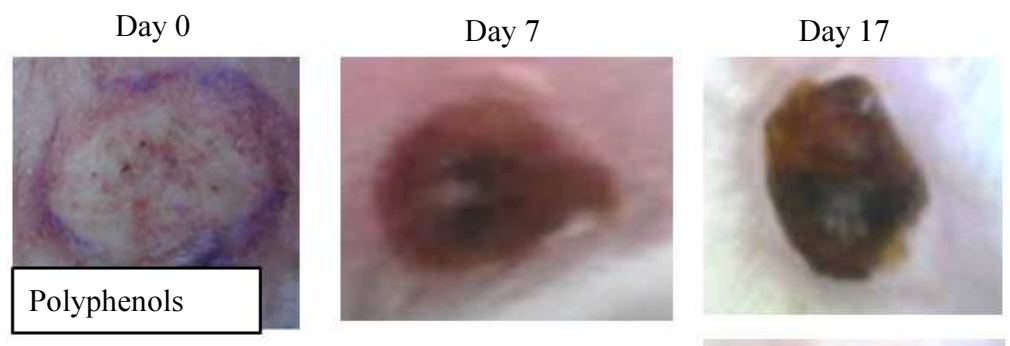

$$
\text { Day } 18
$$
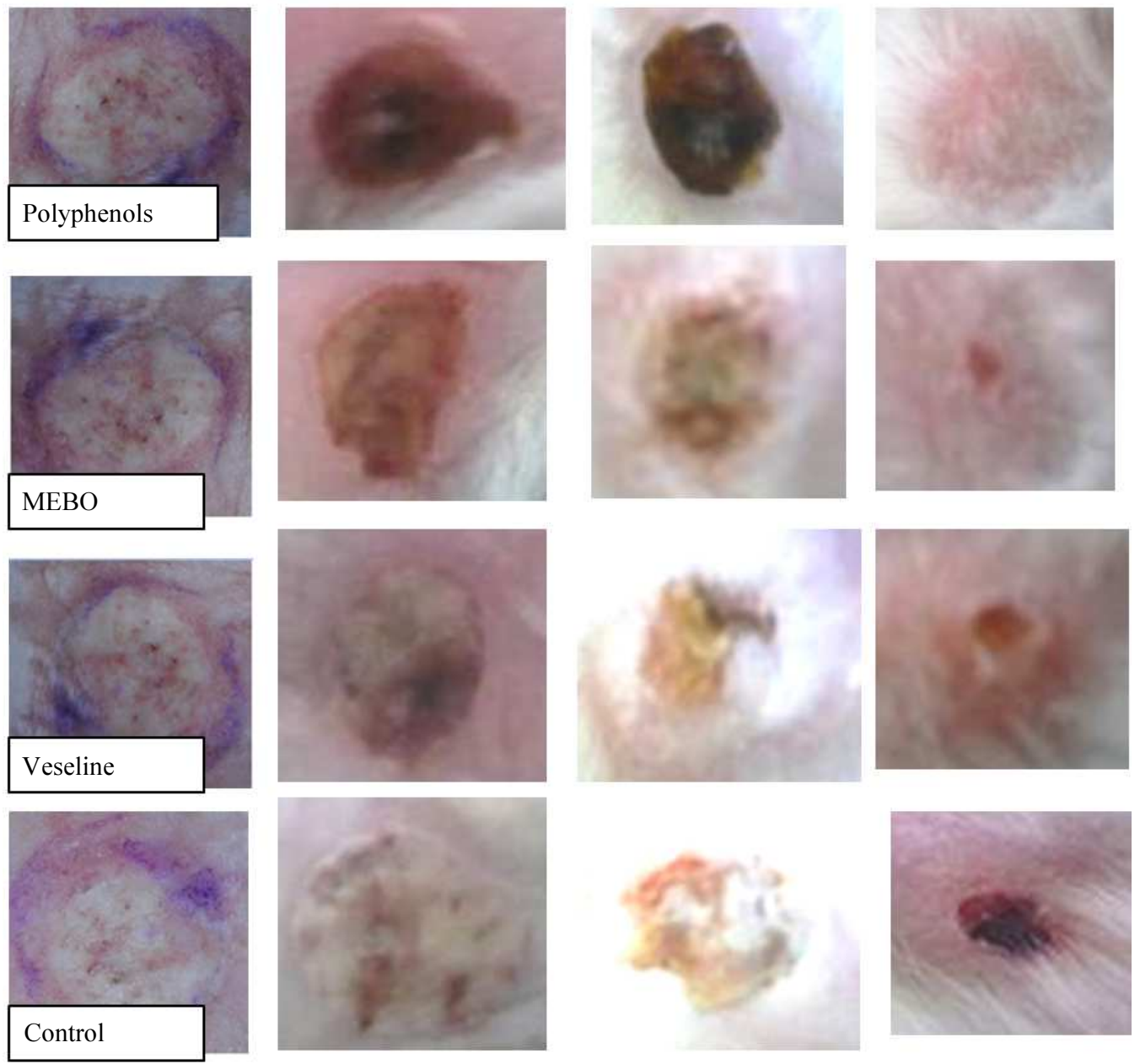

Fig. 5: Chronology of burn healing; Popyphenols: Burns treated with polyphenols, Vaseline: Burns treated with pure vaseline, MEBO: Burns treated with MEBO ointment and control: Untreated burns 


\section{Discussion}

In the early stages of the healing process, vaseline is able to inhibit the evaporation of wound water, so it is known that a moist physiological environment must be formed in the wound for skin repair and regeneration of damaged tissue. However, prolonged therapy can lead to tissue alteration and maceration (Xu and Xiao, 2003). Contrary to the results obtained by Djerrou et al. (2010) and Maameri et al. (2012) who mention that Pistacia lentiscus fatty oil improves the healing effect from the $4^{\text {th }}$ day, wounds treated with our polyphenol extract show the greatest contraction percentages at the end of the inflammatory phase $\left(8^{\text {th }}\right.$ day $)$, from the planimetric point of view, this extract promotes the inflammatory phase gradually, which is essential to the smooth running of the scar process.

Ait-KaciAourahoun et al. (2016) showed that; the leaves of the plant cytisus triflorus are rich in unsaturated fatty acids $(72.51 \%)$, of which alpha linoleic acid and linolenic acid constitute the dominant components of this fraction with a percentage of 13.73 and $48.24 \%$ respectively and saturated fatty acids $(27.43 \%)$ including palmitic acid $(22.29 \%)$. Fatty acids are able to reduce trans-epidermal water loss and thereby increase skin hydration (Dweck, 2007). Alpha linoleic acid and linolenic acid are known for their anti-inflammatory effect and their ability to provide lipids necessary for cell repair and respiration (Loden and Andersson, 1996).

Ait-KaciAourahoun et al. (2015) have also demonstrated that polyphenols in the leaves of the medicinal plant Cytisus triflorus are rich in flavonoids $(52.13 \pm 1.69 \mathrm{mg}$ equivalent of Quercetine/g of extract) revealed a considerable antioxidant activity with a half maximal inhibitory concentration of $19.17 \mu \mathrm{g} / \mathrm{mL}$ and promote $50 \%$ inhibition of DPPH (2,2-diphenyl-1picrylhydrazyl) with antioxidant activity index of 1.04. However, many studies have shown that plants traditionally used as healing agent have immune activation properties, this activation would be the mechanism of healing wounds (Yamada and Kiyohara, 1999; Nergård et al., 2005), as well as the various antioxidants are able to reduce free radicals, preventing the depreciation at the cellular level. They inhibit inflammation, which leads to collagen depletion and offer protection against photon damage and skin cancer (Djerrou et al., 2010).

\section{Conclusion}

In the present study, the dermal burn healing properties of Cytisus triflorus were investigated. In light of the obtained results, it appears that polyphenols of this medicinal plant are more effective than the reference drug "MEBO" and vaseline by shortening the epithelialization period. The study concludes that
Cytisus triflorus polyphenols promote burn wound healing in rabbit's model.

\section{Acknowledgement}

The authors would like to thank all persons who helped to carry out this study, particularly Hadjer Boukria and Imene Gueddah.

\section{Author's Contributions}

Sihem Khadri: Performed the experiments, analyzed and interpreted the study findings, drew conclusions and prepare the manuscript.

Nafissa Boutefnouchet: Designed the research plan, coordinated the implementation of research work and contributed to result analysis.

Youcef Hadef: Participated in experiment's design, coordinated the implementation of research work.

Zouhir Djerrou: Gave suggestions and contributed to the scientific writing and revision of the manuscript.

\section{Conflict of Interest}

The authors declare that they have no conflict of interest.

\section{References}

Ait-KaciAourahoun, K., F. Fazouane and S. Benayache, 2015. Pharmacological potential of Cytisus triflorus l'Hérit. Extracts as antioxidant and anti-inflammatory agent. Der Pharm. Lett., 7: 104-110.

Ait-kaciAourahoun, K., F. Fazouane, S. Benayache and F. Souici, 2016. Fatty acid Profiles of soxhlet and Ultrasonic obtained oils from the promising medicinal legume Cytisus triflorus L'Hérit. Bull. Environ. Pharmacol. Life Sci., 5: 05-09.

Bruneton, J., 1993. Pharmacognosie: Phytochimie, Plantes Médicinales. 2nd Edn., Technique et documentation-Lavoisier, Paris, ISBN-10: 2852069113, pp: 915.

Djerrou, Z., Z. Maamari, Y. Hamdi-Pacha, M. Serakta and F. Riachi et al., 2010. Effect of virgin fatty oil of Pistacia lentiscus on experimental burn wound's healing in rabbits. Afr. J. Trad. CAM, 7: 258-263. DOI: 10.4314 /ajtcam.v7i3.54788

Dweck, A.C., 2007. Herbal medicine for the skin. Their chemistry and effects on skin and mucous membranes. Personal Care Magazine, 3: 19-21.

Guilbaud, J.L., H. Carsin and Y. LeGulluche, 1993. Brûlures. Encyclo Medchi, Paris.

Hamdi-Pacha, Y., A. Belkhiri, M. Benazzouz, L. Benhamza and L. Bensegueni, 2002. Evaluation de l'activité cicatrisante suite à des brûlures expérimentales de quelques plantes algériennes. Revue Méd. Pharm. Afri., 16: 1-7. 
Koechlin-Ramonatxo, C., 2006. Oxygen, oxidative stress and antioxidant supplementation, or another way for nutrition in respiratory diseases. Nutrit. Clin. Métabol., 20: 165-177.

DOI: 10.1016/j.nupar.2006.10.178

Loden, M. and A.C. Andersson, 1996. Effect of topically applied lipids on surfactant-irritated skin. Br. J. Dermatol., 134: 215-220.

DOI: 10.1046/j.1365-2133.1996.978714.x

Maameri, Z., K. Beroual, Z. Djerrou, S. Habibatni and B. Benlaksira et al., 2012. Preliminary study to assess cicatrizing activity of honey and Pistacialentiscus fatty oil mixture on experimental burns in rabbits. Int. J. Med. Arom. Plants, 2: 476-480.

Marston, A. and K. Hosttmann, 2006. Separation and Quantification of Flavonoids. In: Flavonoids: Chemistry, Biochemistry and Applications andersen, O.M. and K.R. Markham (Eds.), Taylors and Francis, ISBN-10: 0849320216, pp: 1-36.
Nergård, C.S., 2005. Immunomodulating pectic polymers. PhD Thesis of Scientiarum, Departement of Pharmacognosy, School of Pharmacy, University of Oslo, Norway.

Rice-Evans, C.A., N.J. Miller, P.G. Bolwell, P.M. Bramley and J.B. Pridham, 1995. The relative antioxidant activities of plant-derived polyphenolic flavonoids. Free Rad. Res., 22: 375-383.

DOI: $10.3109 / 10715769509145649$

Srivastava, P. and S. Durgaprasad, 2008. Burn wound healing property of Cocos nucifera: An appraisal. Ind. J. Pharmacol., 40: 144-146.

Sundararajan, R., A. Bharampuram and R. Koduru, 2014. A review on phytoconstituents for nephroprotective activity. Pharmacophore, 5: 160-182.

$\mathrm{Xu}, \mathrm{RX}$. and M. Xiao, 2003. The mechanism of burn regenerative therapy and wound healing. Chinese J. Burns Wounds Surface Ulcers, 4: 262-271.

Yamada, H. and H. Kiyohara, 1999. ComplementActivating Polysaccharides from Medicinal Herbs. In: Immunomodulatory Agents from Plants, Wagner, H. (Ed.), Birkhåuser, Basel, pp: 161-202. 